\title{
Proceedings of the operations research training workshop: Mainstreaming NFP in the public sector, August 15-18, 1996
}

Family Planning Service

Philippine Federation for Natural Family Planning

The Family Planning Operations Research and Training (FPORT) Program

Population Council

Follow this and additional works at: https://knowledgecommons.popcouncil.org/departments_sbsr-rh

Part of the Demography, Population, and Ecology Commons, Health Services Research Commons, and the International Public Health Commons

How does access to this work benefit you? Let us know!

\section{Recommended Citation}

"Proceedings of the operations research training workshop: Mainstreaming NFP in the public sector, August 15-18, 1996," Workshops. Manila: Philippines Dept of Health, Family Planning Service and Population Council ANE OR-TA Project, 1996. 
Proceedings of the

\title{
OPERATIONS RESEARCH TRAINING WORKSHOP: MAINSTREAMING NFP IN THE PUBLIC SECTOR
}

\author{
August 15-18, 1996 \\ Titay's South Beach Resort \\ Boracay, Aklan
}

Sponsored by

Family Planning Service

Department of Health

Republic of the Philippines

Philippine Federation for Natural

Family Planning

and

The Family Planning Operations Research and Training (FPORT) Program

The Population Council, Manila

Asia Near East Operations Research

and Technical Asistance (ANE OR/TA) Project ${ }^{1}$ ${ }^{1}$ The ANE OR/TA Project is funded by the US Agency for International Development, Office of Population,
Health and Nutrition, under Contract No. DPE-3030-C-00-0022-00. 


\section{TABLE OF CONTENTS}

Page

Introduction and Summary

Welcome Remarks Marilou P. Costello

Host Country Advisor

The Population Council, Manila

Operations Research as a Tool for

Marilou P. Costello

Improving Service Delivery

Illustrative Examples of OR Studies

A. Diagnostic Studies

Situation Analysis in India

Saumya RamaRao

Program Officer

The Population Council

New Delhi

The Bukidnon Drop-out Study

Michael A. Costello

13

Research Associate, RIMCU

Xavier University

B. Intervention Studies

An Evaluation of a Family

Planning Intervention

Providing RTI Services at the

LGU Health Centers

Identifying, Defining and Justifying the Research Problem
Fely David

Director, SSRI

Central Philippine University

Edwin Reuel Ylagan

Program Officer

The Population Council, Manila

Michael A. Costello 
Overview of Research Techniques

Study Design

Sampling and Data Collection

Tabulation and Analysis of Data

Summary of the Session

Dissemination of Research Findings

Utilization of Study Findings
Virgilio Aganon

Consultant

The Population Council,

Manila

Michael A. Costello

42

Edwin Reuel Ylagan

44

Jocelyn Ilagan

47

Medical Specialist III

Family Planning Service

Department of Health, Manila

Appendix: List of Participants 


\section{INTRODUCTION AND SUMMARY}

This report summarizes the proceedings of the Operations Research Training Workshop: Mainstreaming Natural Family Planning In the Public Sector, which was held on August 15-18, 1996 in Boracay, Aklan, Philippines. The workshop was sponsored by the Philippine Federation for Natural Family Planning, the Family Planning Service of the Department of Health, and the Family Planning Operations Research and Training (FPORT) Program of the Population Council, Manila.

Program managers and health officials from Palawan, Bulacan, Leyte, Zamboanga City, and Legaspi City were trained in operations research (OR), to enhance their understanding and appreciation of OR and its role in the process of integrating the Natural Family Planning (NFP) technology in the public health sector.

The training workshop was conducted with the following specific aims:

1. To increase the appreciation for operations research as a tool for improving service delivery;

2. To identify an NFP service delivery models and to be piloted for integration at the public health sector clinics.

3. To identify OR issues in the NFP integration at the public health sector clinics.

4. To develop an action or re-entry plan for installing NFP services in the local government units.

To concretize the process of operations research, results of several diagnostic and intervention studies were presented by resource persons from university-based research institutions and from the Population Council. The participants also reviewed the fundamentals 
of research methodology (identifying, defining, and justifying the research problem; objectives and hypotheses; study design; sampling and data collection; tabulation and analysis of data). The NFP technology was presented by the PFNFP staff.

A process for identifying a particular NFP service delivery model for integrating within the public health sector was initiated and facilitated by the staff of PFNFP. This consisted of a validation exercises with the field staff and the representatives of DOH. It was decided that the model to be piloted was model 4, consisting of nurses and midwives (non-autonomous NFP user) conducting Fertility Orientation Session (FOS) and Initial Instruction (II) but backed up with community volunteers who are NGO/PO-NFP autonomous users conducting the following activities: (1) Follow-up (2) Husband Education Session and (3) Couple Education Session.

The workshop ended with a discussion on planning the dissemination strategy and the utilization of OR study findings. The final activity was a brainstorming session where the group identified certain issues that OR can address in mainstreaming natural family planning in the public health system. 


\section{WELCOME REMARKS}

\section{Marilou Palabrica-Costello, Ph.D. \\ The Population Council, Manila}

Esper has already welcomed all of you, so all I have to do this morning is to "second the motion", so to speak. We in the Population Council are very gratified that all of you responded positively to our invitation to attend this workshop. I know that you are all very busy, yet you took the time to come here. Thank you for that. I hope that when we all go back, we can say that these four days were certainly worth our while.

Just a few words about the OR program - the FPORT (Family Planning Operations Research and Training Program) which has been established in the Department of Health, under the Family Planning Service and coordinated by the Population Council. Funding for this activity is provided by a grant from USAID to the Asia Near East Operations Research and Technical Assistance Program of the Population Council, New York. The program's objective is to improve, through Operations Research and Technical Assistance, the "quality, accessibility, and cost effectiveness of family planning and maternal health (perhaps we should say 'reproductive health') delivery systems in the country and to strengthen the institutional capacities to use OR as a management tool to diagnose and solve service delivery problems."

Note that this quotation talks about using OR. This means that we most certainly are expecting that this workshop will end up having a real impact upon the 17 LGUs represented here today. We want this to be more than just another academic exercise. For OR is like any other tool -- it is meant to go beyond the lecture hall and to be used out there in the real world.

The FPORT has been in operation in the Philippines for the last four years. Other countries that are involved in this program include: India, Bangladesh, Egypt and Indonesia; and, to a certain extent, Thailand, Pakistan and Vietnam. We have some publications which have been provided in your kit -- these should give you an idea about the focus and the range 
of OR activities under the program.

In a little while Dr. David, who is helping us in this activity, and Girlie will be explaining the objectives of this workshop. My own personal goal, is really quite simple: I hope to turn all of you into OR believers by the end of your stay in Boracay. This is my challenge not only to you but also to the resource persons. With the quality of our participants and resource persons coupled with the uniquely beautiful ambience of our surroundings, I have no doubt that we can achieve this objective. Thank you very much and welcome again to all of you. 


\title{
OR AS A TOOL FOR IMPROVING SERVICE DELIVERY
}

\author{
Marilou Palabrica-Costello, Ph.D. \\ The Population Council, Manila
}

Operations research (OR) is a very practical activity. There are so many misconceptions about OR which I hope that we can clarify this morning. One of the reasons for this is because in the past, the experience of research in this country has generally been to focus on basic research. Another difficulty is that the program managers often believe that operations research is something very technical, something that researchers have to be the one to do and that all they can get out of it would be the final section of the report which lists the recommendationss from the researchers. In line with this there is the associated idea that they (the program managers) are not supposed to participate in the OR research process since this is not their line of specialization. Later on, you are going to find out that there is really a need for both researchers and program managers to work together. As you just saw in the video, the program manager has a key role in the implementation of operations research.

OR is a "primary means for supporting the essential planning, coordinating, training and evaluating functions of health and family planning programs." Another way of looking at OR is that it is a "process, a perspective, a mentality, a way of identifying and solving program problems." A characteristic of OR is that it must be timely. As you can see in the presentation, it is something where there is an active participation of the program manager. If the design is such that it calls for a longer time frame, there must be a participation of the program manager in the process itself so that there is a constant update/feedbacking about the lessons learned as the conduct of the research goes on. In order for the results to be useful for the program manager, they must be presented in a layman's language so that they will be understandable to program managers or to somebody not necessarily trained for research. 


\section{What are the Five (5) Steps of OR?}

1. Problem identification process.

2. Identify different strategies that might solve the problem.

3. Strategy experimentation or evaluation.

4. Dissemination of the findings or research results.

5. Utilization of the research results.

We wanted to underscore how important it is for the researcher to work in partnership with the program manager. In the past, it has often been the case here in the Philippines that researchers work independently of program managers and policy makers. As a result, many useful findings from our researchers have often not been utilized. The main reason for this is that there was no attempt on the part of the researcher to begin with a practical problem that was truly defined for them by the program managers. If researchers want to do OR they must not focus on their own pet theories but rather to be concerned with the concerns of program managers.

OR studies focus on service areas under the control of the program manager. Therefore, we have to look at areas under the control of the program manager. We want to do something about components of the program that can be manipulated by the program managers. Broadly speaking there are seven such components, namely:
1) Training
2) Logistics
3) IEC
4) Service delivery
5) Outreach
6) Supervision
7) Management information system 


\section{There are three types of OR Studies:}

1) Diagnostic study - This is like an exploratory study. You know there is a problem and you are trying to understand what are the factors/determinants which lie behind it. You are therefore trying to pinpoint the variables that seem to be affecting the existence of the problem. These studies will generally require a cross-sectional or a prospective type of design.

2) Intervention study - This is something like an experiment. You need this when there is a particular intervention that has been put in place and you want to find out whether this intervention really did make an impact or if it really did solve the problem. In a sense, you are evaluating the intervention. You need a specific design which would often bring in a comparison group: e.g., a pretest or a posttest type of design.

3) Evaluative study - This is very similar to the intervention study because of its evaluative component. As such, it will generally call for some kind of comparison or a pretest or posttest kind of design. In this particular case, it could be a program that has been put in place for some time and you are trying to evaluate the impact of a particular program.

In summary, what we mean when we say OR cycle is that you begin with the diagnosis of the problem. Later, you select different options. This generally involves a procedure of strategy selection where you choose the solution that seems to flow naturally from the diagnosis of the problem. You are now going to test those strategies. Then you go to the step of disseminating your findings and eventually in utilizing them. Ideally, you will go through this full process for all your research problems.

I think that it is very timely as we begin to mainstream the NFP to learn this process and to see how it can help you as we install NFP. We know that there will be a lot of issues 
coming up and we would like to use this opportunity to learn about OR and see how it can be used to solve some of the service delivery problems that might occur during the process of installing this technology in the public sector. 


\section{A DIAGNOSTIC STUDY: SITUATION ANALYSIS IN INDIA}

Saumya Rama Rao, Ph.D.

The Population Council, New Delhi

A diagnostic study is one where you describe an existing situation. Going back to the OR cycle that Marilou was talking about, a diagnostic study is what you do before you put an intervention into place. I will now present to you a diagnostic study that was done in India. To give a little background on this -- the study was undertaken in the state of Uttar Pradesh in India. This particular state has a very low contraceptive prevalence rate and the Population Council is working there in two specific areas. Before proceeding further with its work in these two places, the Council wanted to know the readiness of the public sector system there to provide health care services. This was basically the motive for conducting the study.

The objectives of this diagnostic study, which used the situation analysis approach, were: (1) to measure the infrastructure and support capacity of the public sector system to provide family planning (FP) services; (2) to find out what are the elements of the quality of care and which of these elements was lacking when FP services were provided; (3) to find out what are the types of outlets through which a person in the village could get access to FP commodities and services; and (4) to find out the involvement of Village Health Practitioners (VHP) in providing both maternal and child health services and FP services.

To answer these questions, nine different types of questionnaires were developed. The respondents to most of these questionnaires were health personnel who were working in the public health care system. There were different levels of personnel like medical officers, nurses, midwives and so forth. FP clients who were also respondents, in particular those who had accepted sterilization, IUD and oral contraceptives. These women were identified through records maintained at the service delivery sites. Basically, they were interviewed about the quality of services that had been provided to them. Other people interviewed included 
shopkeepers and village health practitioners.

This survey was conducted at two different sites called Agra and Sitapur. The number of health centers or service delivery points that were covered were of two kinds. There was what was known as the primary health center (this is something like the rural health unit here in the Philippines) and the subcenter, which is a smaller facility acts as the primary health center just like the barangay health center. The study took place in the summer of 1995.

Now I am going to present to you some very salient findings from this survey. I will present data on three different aspects. One is accessibility, meaning - what is the accessibility of family planning services in the villages? What we found in this case is that, in $33 \%$ of the village that were covered in the survey, there were shops which sold condoms. Similarly, 25\% of the villages had a village health practitioner in place. Not all of the villages may have a rural health unit or a barangay health post, so we looked at the availability of health services in the non public sector as well. This included private sector shop sand also the village health practitioners. Then we looked to see if there were any trained traditional birth attendants: We found that one fifth of the villages had trained traditional birth attendants.

A subcenter services roughly a population of five thousand persons. It is staffed by one nurse. What we found was that in $82 \%$ of the subcenters that were covered, the nurse who was there was the one who was doing IUD insertions. Surprisingly, though, less than $40 \%$ of these subcenters had equipments for the insertions. This study therefore highlighted a very important finding that, even though service providers were trained and were doing insertions, there was no working equipment. This raises the question as to how she was able to provide services at all. There were two explanations for this: (1) That the equipment was borrowed from another subcenter or from the primary health center and then the services were provided; and (2) That services were not really being provided at all even though the nurses were reporting that they were doing insertions. In any event, if there is no equipment, this will seriously limit the provision of services. The equipment that should be there at each subcenter includes a 
stethoscope, a sterilizer, a weighing scale, needles, syringes, etc. Among these we found that the most commonly available items were the needles, syringes and thermometers needed for injection administration. However, such other basic equipment as an examination table was available in less than $40 \%$ of the centers while sterilizers were available in only $12 \%$ of them.

Another objective of the study was to look at the quality of care provided by the public health sector system. What we did as a measure of quality of care was to find out the levels of knowledge held by service providers. In general, the doctors tended to be less knowledgeable in oral pills than the nurse/midwife. The reason for this was that doctors were not main providers of the oral pill and so they tended to be less aware about them while the nurse/midwife were the actual precribers. For instance, let's see the responses on side effects. Here we found that nearly $70 \%$ of nurse/midwives were able to report that spotting was a side effect but only $40 \%$ of the doctors said this. In terms of contraindications $20 \%$ of nurses knew that pills were not to be used by women who smoke compared to just $15 \%$ of doctors. This is a very clear indication that many doctors need to be trained on oral pills.

What I am really getting at here is to tell everyone that there were five questions on knowledge of which service providers have to respond. What one should learn from this exercise is that you can measure knowledge in different ways. Maybe for the NFP program you want to devise just those right questions on which you would want to test knowledge. This is one way you could do it.

The third overall objective of the situational analysis was to find out the types of promotional activities that had to be undertaken in the communities to increase demand for family planning services. To learn about this, we surveyed the availability of IEC materials at both subcenters and primary health centers. Basically what we found out that there was a serious lack of IEC materials and, if any material was available, it was just a poster. There were no flipcharts or other materials on methods of family planning. Also, if any material was available, it tended to be situated at the primary health center. 
In sum, the data that I showed you all relate to three different aspects:

1) What is the accessibility of family planning services?

2) What is the quality of care that is provided?

3) What type of promotional activities are being carried out?

I am well aware that the examples we have shown here may seem to be far away, not only in terms of geographical distance but also for the problem that you are addressing. But you must understand that this study dealt with the availability of family planning services in general. If you consider that NFP is also a family planning method, you can still use this framework to answer certain basic questions. I would therefore suggest that you consider this as a framework and work your questions around it. 


\title{
THE BUKIDNON DROP-OUT STUDY
}

\author{
Michael Costello, Ph.D. \\ RIMCU, Xavier University
}

What we thought we would do this afternoon would be to begin by giving you examples of OR studies. Saumya gave you example number 1 of a diagnostic study and I am going to give you example number 2. Let's call it "The Bukidnon Drop-out Study". It was carried out by my institute (RIMCU), by Prof. Lita Sealza in close collaboration with Dra. Edith Abocejo who is the Regional FP Coordinator of Region X. I served as an informal consultant at many stages, so I do have an idea of what was going on. Perhaps I could already note the very first fact about this study is that it exemplifies the word collaboration that came out this morning in Marilou's talk. As she pointed out, one of the distinguishing characteristic of operations research (OR) is that there must be a very close partnership between the program manager and the researcher. This study does illustrate that because it began at a workshop like this, the very first OR workshop held about three years ago in Davao City.

When you read your OR handbook, it talks about problem identification. They said that another characteristic of a diagnostic study is you have an idea, a hunch. More typically, of course, you have many hunches, many hypotheses. There are at least two "possible and plausible" answers or reasons for the existence of a certain problem that has cropped up in the

program. That was indeed true for the drop-out study. Why was that? I will give you a hint: the original title of the project was "A Diagnostic Study of the Drop-Out Rate in Bukidnon". When Lita finally get around to writing that up into a journal article, it was entitled "Quality of Care and Family Planning Drop-Outs in Bukidnon Province". So by the end of the study, she found out that one of the main reasons is poor quality of care, lack of follow-up, or the women were not very happy about the service they were given and that was tending to make them not to come back. But there were other possible hypotheses way back at the beginning. You know at the beginning everything is all very fuzzy. We were thinking that maybe it's logistics or maybe it's a matter of institutional problems (opposition of church or family). Another possible reason 
for dropping-out was that the women want to have a baby. So way back at the beginning there was confusion and there were many possible answers. By the end of the study, though, there was a little more light coming through.

One more thing about diagnostic studies. This morning we got off a little bit on the wrong foot when we had this digression about the difference between an intervention and an evaluation study. For now let us just keep our focus on the distinction between diagnostic and intervention studies. That one is a clear distinction and the one that we really need to know. Diagnostic: What really is the problem and what is its cause? In comparison, for an intervention study, we think we have a solution and we are going to pilot test to see if it really works. Again, I think that is a very useful distinction for NFP people because I am sure you're going to run into problems of implementation, getting a large number of Filipinos to correctly use NFP. You might need a diagnostic study to see what is going on out there. Let's say, for example the contraceptive failure rate -- if there are cases where women get pregnant while using NFP, what seems to be the problem? Later on if you have the different models, it seems to me that that would be a very good starting point for an intervention study.

What does quality of care mean? I am sure many of you are familiar with this. It is a term somehow associated with the Population Council. Judith Bruce and Anrudh Jain are two of the authors that have written extensively about this. What is the basic logic? Let us go back in the 1970s: the population explosion, too many people in the world, rapid population growth. Do you remember that sort of scenario? Back then there was a very heavy emphasis on getting more people into the program. We needed acceptors as though that was the only thing that mattered. In other words, the emphasis was on quantity, not quality. The problem with that is, if you treat people and get them in and then there is no follow-up, no attention or care being paid to them, there will surely be drop-outs. So the downside of big numbers of acceptors is that you usually also get big numbers of drop-outs. Theoretically, there is a connection between quality of care and a drop-out problem. Bruce and Jain have argued that if yo go a little slower, pay a little more attention to each of your clients, they are going to respond by staying with you. 
In fact they may go out and become your best recruiters. So your overall acceptance level may stay high if you will do a good job on quality of care.

What are some of the main dimensions of the quality of care framework? One dimension is the idea of a free and informed choice. But how can you have a real choice if there is no expanded selection of methods? Lita found in her study that in many of the clinics of Bukidnon supposedly there was a "cafeteria" but in reality that was not the case. The big three were oral contraceptives, IUD and condom. There's really nothing beyond that. Many clinics, in fact, were being staffed by midwives that were not trained to administer IUDs. In addition, free choice means you must give your clients a lot of information so they can make a wise decision based on their own needs. For example, if there are going to be some side effects, you should be telling them about these right from the beginning. Many situational analyses, though, find that the providers are not given much orientation or warning about possible side effects. In some cases nothing at all is said to the poor client. Another dimension has to do with acting in a friendly and caring way to the client. Finally, there's technical competence - does the provider really know what she's talking about when she administers pills; is the provider aware that if a woman is a heavy smoker she should not be getting pills; do they use gloves when they insert IUDs, etc? Those are the major dimensions of quality of care.

Now, let's go back to Prof. Sealza's study. She drew a sample of four hundred women who had been listed in the DOH records as family planning acceptors at anytime during 1992. These were in twenty different barangays of Bukidnon. We got back to them on October 1993 and one of the questions we asked was: are you still using the family planning such as pills, condom, etc? The sample of four hundred was then broken up into two groups. One hundred and fifty of the clients had become drop-outs while the remaining two hundred and fifty were still with the program. So now Lita was able to compare the two groups. Comparison is usually a defining characteristic of an OR study design. In this case we are going to compare drop-outs to those who stayed in the program. 
Let us just pick out a few findings. The typical answer for dropping out of the program was because of side effects. In more than half of the cases the woman said "I experienced side effects". Thirty five percent claimed that they hadn't been given any warning about side effects. This response was particularly common among those who were using contraceptive pills. Other reasons for dropping out were: the desire to have another child or it is against their religion. But these were mentioned by only a few so these did not appear to be a major reason for dropping out. Another finding was that most health providers were observed to be friendly and approachable by their clients, although not all. Home visits turned out to be a weak point. The community health workers did not seem to be going out to the barrios. Only one quarter of the women had ever had a home visit. On the question about informed choice, ten percent of the women were not given an explanation for any method and sixty percent were given an explanation for only one method. Thus, only thirty percent of the women had an explanation of two or more family planning techniques.

Let us compare the drop-outs to those who stayed with the program. Was there a difference in the quality of care? The answer is yes and it was "statistically significant". Meaning to say that those who dropped-out were more likely to receive a lower quality of care. The drop-outs were considerably more likely to say that nobody had ever warned them about side effects. Naturally they panicked when side effects happened to them and they said "I'm going to stop right now". Again that idea of the provider being willing to spend a little bit time to explain things can have a pay off later on, in terms of not dropping-out. Those who dropped-out were also more likely to say: "No, I was not satisfied with the service" or "no, she wasn't friendly".

As a sociologist, I have to admit that very often finishing up the study report is the "end of the line". But in OR you must have dissemination and utilization. There was therefore a research dissemination seminar for this study in Cagayan along with a national dissemination seminar in Manila. There were also a lot of informal exchanges between Prof. Sealza and Dr. 


\begin{abstract}
Abocejo. They worked together to write the report and a journal article and they also had the study featured in the PopCouncil Alternatives newsletter. They really did make an effort to disseminate and spread the message out. On utilization, the Family Planning Service in Region $\mathrm{X}$ changed its training and supervision procedures to put a bigger emphasis upon quality of care. I would like to think that this study also played some sort of role in what is going on here today in the sense of what I mentioned before about a true cafeteria -- really having a wide variety of choices. This study showed that when women accept a method that they don't really want they eventually end up dropping-out. So I'm sure many of these women in Bukidnon wanted to use NFP but it wasn't being given to them. So quality of care means among other things that we should "let a hundred flowers bloom" and let NFP also be mainstreamed.
\end{abstract}




\title{
AN EVALUATION OF A FAMILY PLANNING INTERVENTION
}

\author{
Fely David, Ed. D. \\ SSRI, Central Philippine University
}

This FP intervention study was conducted to test and evaluate the effectiveness of two approaches in improving FP acceptance, namely, the use of male peer counselors and BHWs as educators and motivators of FP. It was expected that by the end of project implementation (December 1995), the contraceptive prevalence rate (CPR) in the experimental areas should have increased by at least two percent.

This is a collaborative project of Save the Children, the Department of Health Region VI, the Provincial Health Office of Iloilo and the local health offices of the three municipalities in Iloilo Province: Maasin (BHW area), Anilao (male motivator area), and San Dionisio (control area), with funding support from UNFPA. The project has four major components, a) training, b) field implementation/motivation, c) monitoring and supervision, and d) research. Seventy BHWs and 70 male motivators had been programmed to be trained as FP motivators and communicators. They would then be mobilized to promote FP under the supervision of RHMs and PHNs in their respective localities.

During project duration, several research activities were undertaken, including a) preliminary qualitative study, b) a baseline survey, c) mid-term evaluation, d) post-project qualitative investigation and e) a post project evaluation survey. Research results were disseminated through research utilization workshops at the local and national levels.

\section{Objectives}

The evaluation study aimed to determine and compare the effectiveness of trained BHWs and male peer counselors as FP educators and motivators in improving the knowledge and attitudes about FP and eventually increasing FP practice in the target areas as well. It was 
hypothesized that the FP interventions will significantly increase the CPR, and also add to local knowledge about family planning and attitudes towards family planning and that improvements on these indicators would be better in the experimental areas than in the control areas. It was further expected that between the two groups of motivators, the male motivators will perform better than the BHWs. Thus, improvement in CPR were expected to be sigficantly higher in Anilao than in Maasin.

\section{Major Findings}

1. Seventy BHWs and 70 male peer counselors were trained on family planning and effective communication in April and June 1994, but only 58\% of the latter finished. Additional male motivators and replacements for those who dropped out were recruited and trained in June 1995, a year later.

2. Immediately after the training, the BHWs and male motivators were mobilized. The planned supervisory meetings between the midwives and the motivators in both areas, however, failed to materialize during the first half of project implementation. This happened because of lack of follow-up and cases of drop-outs especially among the male motivators. Provision of travel and food allowance to the motivators later revived the monthly meetings and improved attendance. Even so, attendance still fell short of the expected.

3. At mid-term stage between 60 to 70 percent of the BHWs, as compared to only about one-third of the male motivators were still active. At endline stage, about 70 to 80 percent of the BHWs while only about 40 to 50 percent of the male motivators remained active. Their cumulative accomplishment report from July 1994 to December 1995, showed that the BHWs convinced more acceptors than their male counterparts did.

4. Condoms and NFP were the most popularly accepted methods in the BHW area, while 
pills was the most popular in the male motivators area and in the control area. Condoms ranked second in the former, while NFP ranked second in the latter.

\section{Project Effects and Impact}

1. The training improved the BHWs' and the male motivators' knowledge and attitudes on FP. They acknowledged that the training made them more knowledgeable about FP. Their attitudes towards FP which were already favorable at baseline stage, remained so till the end of project implementation.

2. The knowledge about family planning held by married women of reproductive age (MWRA), which was already high at the baseline stage, exhibited favorable changes in all study areas.

3. The attitudes of the MWRAs towards the practice of family planning remained favorable in the three study areas from baseline to endline stages.

4. CPR significantly improved by 23.3 percent in Maasin, the BHW area, and by 12.3 percent in Anilao, the male motivators area. The 11.1 percent advantage of Maasin over Anilao is statistically significant.

5. NFP had the highest prevalence in all areas both before and after project implementation. The prevalence of pill use increased in all areas, but only the increase in the BHW area was significant. The number of ligation acceptors also increased in all areas, but only the increase in the male motivators area was significant. The use of condom, IUD, and injectibles also increased, but not significantly in all areas.

6. The most common sources of FP supplies among the contraceptive users were the RHUs and the BHS in all three areas both before and after project implementation. 
7. Fear of side effects of other methods was the top consideration in choosing the FP method to practice. The desire for more children, fear of side effects and lack of knowledge about FP were the top three reasons why some couples do not practice FP both at baseline and endline stages.

\section{Conclusions}

1. The findings of the study support the hypothesis that the change in CPR is significantly higher in the experimental areas than in the control area which makes it safe to conclude that the motivators' training and mobilization had significantly contributed in improving their performance. Between the trained BHWs and the male motivators, however, the former performed better than the latter.

2. The MWRAs knowledge on and attitudes towards FP which was already favorable before project implementation remained to be so till after project implementation in both control and experimental areas. Apparently, the project has helped sustain this favorable situation.

3. The MWRAs and their spouses as well as the rural health team and the motivators fully recognize that the men could be effective FP motivators and communicators. The male motivators are perceived to be more effective than female motivators especially if the FP campaign is directed not only to the women but also to men.

4. The fact that the active male motivators performed as well as the active BHWs indicates that interested and committed male motivators can truly be effective FP educators, if properly selected and motivated.

5. Women-oriented FP methods are still more popular than the male oriented ones even in Anilao, the male motivators area. This could be attributed to the fact that the promotion of male-oriented FP methods was not emphasized during the training especially among 
the male motivators. The fact that male-oriented methods (condoms and vasectomy) are difficult to promote because of a cultural bias against them was further confirmed by this study. The absence of facilities for vasectomy services is another factor to consider in this case.

\section{Recommendations}

1. Family planning programs should involve men not only as FP targets, but also as motivators and communicators. Only interested and commited men in the community should be recruited, trained and mobilized. This suggests the need for a clear selection criteria and a strict adherence to the requirements.

2. The training must include modules on the practical application of the theoretical concepts and procedures. A detailed module on the different FP methods should include the advantages and disadvantages of each method, how they are used and the expected consequences of their usage. The motivators must be prepared to answer basic questions about FP, if they are to maintain a certain level of credibility and respect in the community.

3. The reporting system must be further simplified, or another strategy that does not require them to do paper work may be devised. Motivators can be made to work in tandem with BHWs to help them record their accomplishments.

4. Close monitoring and follow-up of motivators must be maintained. Since it is difficult for the motivators to go to the health stations, the RHMs should schedule regular field visits to personally meet with the motivators in their "territory" (home or workplace maybe). This of course implies travel support for the RHMs.

5. If the LGUs want an effective FP program in their community, then a specific budget must be allocated for this purpose, so that even if the NGOs leave the community, the program initiated by the NGOs can still be sustained. 
6. The involvement of men in the FP program must be continued and expanded in other areas in the region. However, the lessons learned from this study must be used in improving the strategies of any expansion or replication project. 


\title{
PROVIDING RTI SERVICES AT THE LGU HEALTH CENTERS: AN INTERVENTION STUDY ON SYNDROMIC MANAGEMENT
}

\author{
Edwin Reuel Ylagan, M.D. \\ The Population Council, Manila
}

\section{Background}

Field intervention studies test new approaches to overcoming a program problem. Sometimes we already know the factors responsible for causing the problem, but we still have to determine which would be the most cost effective solution for overcoming the problem. Field intervention studies also test new service delivery modes. A field intervention study is prospective and longitudinal. This means that, if you do an intervention now, you will have to observe it over time and then see afterwards whether that intervention has made an effect and provided the solution to the problem that you are seeking. The design is therefore experimental or quasi-experimental.

Our particular example in this case is "Providing RTI Services at the LGU Health Centers: An Intervention Study on Syndromic Management." Syndromic management is an approach developed by the World Health Organization (WHO) for diagnosing and treating reproductive tract infections (RTIs) because, in the past, RTIs were managed through clinical or etiological diagnosis. They have now come up with a new approach which they call the syndromic approach wherein a patient is managed based on the signs and symptoms that she is presenting. For example, a woman comes in with a vaginal discharge which is cheese-like and white so it is probably a fungal infection. They would treat it as a fungal infection. There is no need for an expensive laboratory test which would take a week to know really what is causing it. In a nutshell, that is what the syndromic approach is.

Earlier we were talking about the focus on population programs wherein there was a shift from basically a demographic approach to one of reproductive health. One of the issues of reproductive health is reproductive tract infections. Furthermore, when we talk about RTIs, 
we're not only talking about the sexually transmitted diseases (STDs) but also about endogenous infections and as well as iatrogenic infections meaning infections introduced by the service providers especially when inserting an IUD or performing a tubal ligation . We found out through our literature review that RTIs are extremely widespread among women from the developing world. They have reported in studies done in Egypt and India and also in local studies, like the Davao study and the 1993 Safe Motherhood Survey. Despite strong programmatic and epidemiologic reasons for considering the FP program as a focal point for prevention and control of RTI, there are numerous problems attendant to this. If we will look at the "Clinical Standard Manual of the FPS", we know that RTIs are one of the priorities, but we know as well that there is problem in implementation because diagnosing RTI is a very complex problem . It is very expensive. The local LGUs' health centers can not readily come up with the financial resources for this. There are also a lack of skills among FP personnel. We would often hear about a woman with vaginal discharge who would come into the health center and then what they do is to refer her to the STD or the social hygiene clinic. Of course she wouldn't go because that clinic is associated more often with commercial sex workers. I am sure most of you would rather seek private practitioners in a case like that.

We also consulted the Department of Health, STD-AIDS Program, the Women and Safe Motherhood and even with the Family Planning Service. They all reviewed the proposal in the initial parts of the study. In selecting the strategy, we decided that the syndromic approach is the best way to manage RTI at this level, simply because of the lack of trained personnel. Also, the patient will be treated right away at first visit. Even if there is no doctor, the nurse or midwife could already manage the RTI.

\section{General Objectives}

To assess and enhance the effectiveness of the syndromic approach towards diagnosing RTIs and to improve RTI management within the FP/MCH Programs of the selected LGU health centers. 


\section{Study Intervention Sites}

Three study areas have been targetted. These are: Quezon City, Cagayan de Oro and Misamis Oriental. Besides the fact that they are all LPP areas, these places were chosen mainly for their OR capability (location near a research center with OR capability) as well as their access to technical assistance from other agencies working on the same concerns: JHPIEGO, POGS, PATH, the STD/AIDS Unit of the DOH and the World Bank funded Urban Health and Nutrition Project. Control areas will be selected as based on their similarities with the experimental areas on a number of key health and sociodemographic characteristics.

The three study areas exhibit different demographic characteristics. Quezon City is a large, densely populated urban area within the Manila Metropolitan Area. At present, it operates two well-equipped social hygiene clinics (STD centers) serving between 5,000 to 12,000 clients every year. Cagayan de Oro is a typical medium-sized city located in Northern Mindanao. It is also one of the three sites in the country chosen for participation in the national AIDS Surveillance Project as well as the Women's Health Project. Misamis Oriental is also located in Mindanao and represents a low density, basically rural province. It is a pilot area for the Reproductive Health Program of the DOH.

\section{Study Activities}

The intervention will involve three components: first, the provision of training to health center staff (physicians, midwives and nurses) in the syndromic approach to RTI diagnosis and management; second, upgrading of laboratory facilities in the health centers; and third, a campaign to increase community awareness of RTIs. Health centers affiliated with the LGUs which are participating in the LPP program will be targeted for this OR study. The potential for institutionalizing OR capacity in these places should be good since the commitment of LGU officials to strengthen their FP program was already obtained as a prerequisite for joining this program.

Diagnosis and treatment will be provided on a per need basis to symptomatic men and women seeking RTI services at rural health centers. Women seeking other services (for 
example, MCH or FP) and exhibiting symptoms of RTIs will also be served. Services will be provided at health centers by the attending physicians, nurses, midwives and community health volunteers.

[ Further details on the study were provided by Dr. Ylagan at this point.]

In formulating your intervention description later on, when you develop your specific concept papers, you probably won't be able to go into so much detail, because of time constraint but you should develop this when you get back to your specific LGUs.

To recap this short lecture, here's what to do in an intervention description:

1. Be as detailed and complete as possible in describing the study intervention.

2. Describe the activities in the order they will occur.

3. Be sure your description of the intervention answers three basic questions:

a. Who will be responsible for implementation?

b. Where will the intervention take place?

c. What activities will be initiated and at what level of intensity? 


\title{
IDENTIFYING, DEFINING AND JUSTIFYING THE RESEARCH PROBLEM
}

\author{
Michael Costello, Ph.D. \\ RIMCU, Xavier University
}

\section{Identifying a Research Problem}

According to Fisher, et al a problem is: a) a perceived difficulty; b) a feeling of discomfort with the way things are; and c) a discrepancy between what someone believes should be and what is. A potential research situation arises when there is a perceived discrepancy between what is and what should be; when there is a question about why the discrepancy exists; and when there are at least two possible and plausible answers to the question.

One of the original OR studies reported in the special issue of the Philippine Population

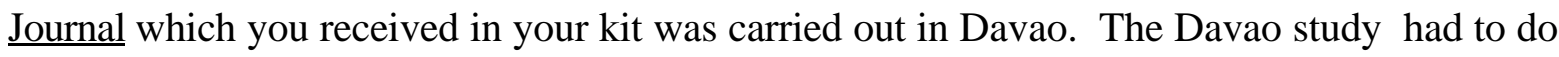
with outreach workers. There had been an earlier study of barangay health workers (BHWs) and one of the questions was: have you ever been visited by your BHW? That was a study which had to do with the tuberculosis campaign if I remember correctly. The study found out that a high percentage of the respondents were saying things like"Do we have a BHW here?" "Who is she?" So there was a discrepancy. We hope that the BHWs are going out into the community, being missionaries who are very zealous in meeting people and talking them about the programs in the DOH. The reality was very different. Local people weren't even aware that they had one much less having the experience of ever being visited by one.

[ A second example of a research problem was then discussed. This was taken directly from the OR handbook - overcoming the distribution problem for oral contraceptives that occurs each year during the monsoon season in "District A".]

In this example, there are several possible and plausible reasons for the problem situation. One or more of these reasons might be correct. Therefore, this is a potential research situation. 
In some situations, it is relatively easy to identify the problem, to define it,

hypothesize the reasons for it, and to conduct research to determine which reason is correct or more nearly correct. The reasons for the supply and logistics problem in the above example could probably be determined fairly easily and certainly would not require an expensive research study.

\section{Defining a Research Problem}

1. Where to look for additional information?

* review of related literature

* examination of current service statistics and agency policies

* talk to knowledgeable informants

* deduce probable explanations from existing theory

2. What sort of information to look for?

* incidence/prevalence of the problem

* differentials (sociodemographic or economic groupings, ecological variations)

* $\quad$ suggested causes of the problem

* $\quad$ suggested solutions for the problem

* $\quad$ areas in need of further research (unanswered questions)

\section{Justifying a Research Problem}

Problem justification has more to do with somehow finding a way to convince the funding agency that your problem is really important and is worth spending time and money on. Of course we all have our own pet ideas and we think our idea is great. But you have to 
convince the hard-headed program managers to spend money and time.

In justification, we have to answer several questions. Will it effect a lot of people? Does it have prospects for success? Is this a big problem? Is lots of money being wasted? Is this a special problem in your place? If so bring it out. You are like a lawyer advocating your case. One last thing, again when you read through this chapter, it will mention in a number of places about close interaction between the researcher and the program manager. So we come back to that issue, too.

A good way to come up with a real problem is to go out and talk to people who are implementing the program. Actually, sometimes even they have a hard time putting their finger on the problem but it has to come out during that interaction. That's the nice thing about these workshops. One thing the PopCouncil is trying to do is to institutionalize linkages between researchers and program managers because out of that linkage something totally new emerges. Working together in partnership we can get all sorts of new, very practical problems to identify, define and justify. 


\title{
OBJECTIVES AND HYPOTHESES
}

\author{
Fely David, Ed.D
}

There are two types of research objectives which should be kept in mind for any research, particularly OR research. One of these is the ultimate objective while the second is the immediate objective. Research objectives give focus to the study. For instance, a while ago, Mike gave us an example regarding the problem of the high drop-out rate. If you'd like to answer this question you have to focus your problem - what do you really want to know and what do you really want to find out.

\section{Ultimate objectives}

These are objectives which describe the expected contribution or implication of the study. This type of objective helps to relate the proposed study to broad social, economic, and health concerns. In simple terms, the ultimate objectives are expected and hoped for contributions. Much more simply, ask yourself the following question: "If I knew the factors that caused, determined or influenced the problem, how would this knowledge help policy-makers, program administrators, or others?" In other words, if you are a researcher and you are not oriented in OR, this has to do with the significance of your study. So this section of the OR concept paper explains the significance of the study: "Who will use the study? How will the results of the study be used?" Most of time you don't see these questions discussed in relation to the objectives of the study. You may find them referred to in the introduction or somewhere else. What you usually find under the section entitled "Research Objectives" is really the immediate objectives of the study.

Let me give you some examples of ultimate objectives: 1) Survey Study of the FP Knowledge, Attitudes, and Practices of Community Influentials in Sri Lanka. "The ultimate 
objective of this study is to increase the involvement of community influentials in health and family planning program activities"; and 2) An Experimental Study to Integrate Communitybased Family Planning Education and Services with Primary Health Care in Two Rural Areas of Cameroon. "The ultimate objective of this study is to develop a rural, integrated, cost-effective family planning and health services system which has a measurable impact on decreasing infant and maternal morbidity and mortality." There are several examples in your manual. Ultimate objectives therefore must be stated in order to provide some assurance that the results of the study will be utilized. If this will happen, how will the program implementors and policy-makers be able to utilize the results of the study?

\section{Immediate Objectives}

The immediate objectives can generally be thought of as involving what most of us call the research objectives. These objectives state what will happen in the study. They relate directly to the research problem situation. They indicate the variables that will be examined and measured. They represent a promise by the investigator that certain activities will take place and specific variables will be examined. At this point we state what we want to do and what we want to find out. However, since OR involves inviduals and agencies these immediate objectives require us not only to specify what we want to find out but it also require us to specify in behavioral terms: Who will do, how much of what, to whom, when, where, and for what purpose?

We will try to answer these questions as we look at the examples. For instance, "The Ministry of Plan Implementation (Sri Lanka) will conduct a survey in 100 randomly selected villages to determine the family planning knowledge, attitudes, and practices of community influentials." Let's go back to our questions:

\footnotetext{
* who will do it? (the Ministry of Plan Implementation)

* whom are they going to study? ( community influentials)
} 
* when? ( optional )

* where? (in selected villages in Sri Lanka)

* what is the purpose? (to determine the FP knowledge, attitudes, and practices)

\section{Hypotheses}

A hypothesis is a statement about an expected relationship between two or more variables that permits empirical testing. Hypotheses are most appropriate for field intervention or evaluative studies. Diagnostic studies do not always require hypothesis statements, especially when they involve an exploratory design.

Study hypotheses serve to direct and guide the research. They indicate the major independent and dependent variables of interest. They suggest the type of data that must be collected and the type of analysis that must be conducted in order to measure the relationship.

When writing hypotheses, it is important to keep in mind the distinction between independent and dependent variables. An independent variable causes or determines or influences the dependent variable. In other words, whenever the independent variable changes, there is a change in the dependent variable. The dependent variable depends on the independent variable. It is the effect, not the cause.

When you're stating your hypothesis, sometimes the relationship is not direct. You don't always have one variable and another variable. Like for instance: "Training will reduce the drop-out rate." We also have intervening variables that interfere by weakening or strengthening the relationship between the independent and dependent variables. In this case, the independent variable is the training. What will training do? Training of the BHWs is expected to improve family planning acceptance. But are you sure that if you trained them that FP acceptance will improve? What if they don't work? Would you expect this to happen? No. So you have also 
to look at the intervening variables. Now, you have three variables that go in the hypothesis: "Trained motivators will help improve contraceptive practice if they are mobilized".

When you are looking at relationships of variables and stating these in the form of hypotheses, you may express your guesses or preliminary questions by looking at two variables and stating the expected relationships, or stating the relationship between the two variables, considering a third variable that may interfere in the relationship. By forcing ourselves to think about these relationships at an early point in the study we will ensure that (1) we collect data on all these factors and (2) we will see how they are actually associated with one another when we get to the data analysis stage. 


\title{
OVERVIEW OF RESEARCH TECHNIQUES
}

\author{
Virgilio Aganon \\ The Population Council, Manila
}

\section{Study Design}

The study design is the plan of action of the investigator in trying to answer the research questions or to get the data to prove or disprove the hypothesis. The objective of the study design is to maximize reliability and validity. Reliability has something to do with consistency of data. Given the instrument that you have and applying that instrument several times you should get the same kind of measurement. You have an instrument that elicits the age of a person by asking the question: "How old are you as of your last birthday?" The validity has something to do with what you are supposed to measure. If you ask the question again: "How old are you as of your last birthday?" Then you got an answer of 42 that should be 42 in real terms or in real life. But if you look at his birth certificate and he is 55, then you didn't have a valid measure.

\section{There are many threats to validity:}

1. History - this is a threat to validity if there is an event in the community that would somehow affect the implementation of the program. For example, the campaign to increase awareness about DMPA might have some historical events that would affect it. For instance, the devolution might have affected some of the statistical measures of the program.

2. Selection - it could be that the population or the sample selected was chosen such that it is concentrated among young women of reproductive age and so therefore the measure that you have is not comparable to a random sample of women. 
3. Testing - this is especially true in a pretest and posttest design which is conducted within a short period of time. The respondent is aware in the type of questions asked in the pretest, and therefore he knows what to answer in a posttest.

4. Instrumentation - you may have two data gathering periods and you may have changed the definitions of some terms, thereby threatening the validity of your conclusions.

5. Maturation - if the innovation takes a long time and the respondents are growing older and more mature (or perhaps less fertile) all this time, it would affect their performance in the posttest.

6. Mortality - in longitudinal studies especially in the medical field, some of your subjects might die, reducing your sample size. Another possibility is that they would move away or stop answering questions.

There are three types of study designs: 1) nonexperimental designs; 2) experimental designs; and 3) quasi-experimental designs. The major distinction between a nonexperimental design and an experimental design is that, in the experimental design, there is a random allocation to the experimental and control groups. Whereas in the nonexperimental design there is no random allocation.

Ethical issues should be taken into account during the selection of the designs. The confidentiality of the information is very important. We seldom get the names of the respondents or if we get the names, we destroy these records once we get to the office. 


\section{Sampling}

There are two types of sampling: the probability sampling and the non-probability sampling. In a probability sampling, each element in the population has a non-zero probability of being included in the sample. While in a non-probability sampling not every element would be included in the sample. Examples of a probability sampling are: simple random sampling, systematic sampling, stratified sampling, cluster sampling and multistage sampling.

If we have a record of all women of reproductive age in a particular community, you can list them down consecutively, say, from one to two hundred (if there are two hundred of them). That is what we call a population of women of reproductive age and that listing is what we call a sampling frame. If, from that listing, we select a random sample size less than two hundred and in selecting that sample we made use of random numbers, that is what we call a simple random sample. Any other procedure is not a random sample. How do you get a sample of twenty out of two hundred using the table of random numbers? Just close your eyes then point your pencil anywhere in the page. Go to the nearest digit and take three digits at a time because the maximum number is two hundred and it is composed of three digits. If that number is anywhere from one to two hundred, that is included in the sample. If that is not between one to two hundred, you proceed to the next three digits to the right and see if that falls between one to two hundred, and so on and so forth. When you have taken twenty of them, the twenty women corresponding to those numbers comprise your random sample.

It could also be a systematic sample, since twenty out of two hundred is ten percent or a sampling fraction of one is to ten. So by using a table of random numbers only once you could generate a random sample using a systematic sample. The estimated number of elements in the larger population is divided by the desired sample size, yielding a sampling interval. The sample is then drawn by listing the population elements and selecting every nth case, starting with a randomly selected number between one and $\mathrm{n}$.

In stratified sampling that would mean that your population could be grouped into several strata wherein each stratum is very different from another one. Let's say a stratum of 
males and a stratum of females. These are two very different populations, especially when you are testing about responses to certain medical procedures. In stratified sampling one stratum is different from the other. In cluster sampling, cluster 1 and cluster 2 or cluster 3 are very much similar to each other. Say if you measure the characteristics in one stratum in terms of stratum mean, stratum mean of stratum \#1 would be very much different from the stratum mean of stratum 2 or stratum 3. While in clusters, the cluster mean of cluster 1 is almost the same as the cluster mean of cluster 2 or cluster 3 . So in cluster sampling, the clusters as a whole are similar to any other cluster but the units within the cluster are dissimilar from each other. In contrast, the units in a stratum are very much similar, but when you compare one stratum with another stratum they are dissimilar.

Multistage sampling is an administrative procedure to make a sampling administratively possible within the time and resources that we have. If we are trying to measure the prevalence rate of NFP all over the Philippines, we need only a sample size of ninety six to get a margin of error which is \pm 10 percent. But this means that you have a sampling frame of the 18 million women in the Philippines from which you will select your sample of ninety six. It is quite impossible to do that administratively and within the resource and time that we have. Instead, we can conduct a multistage sampling wherein first we select a random sampling of provinces, then from selected provinces select a random number of municipalities, then from the municipalities select a random sample of barangays. From the selected barangays, enumerate all the households in the barangays and from the listing of those barangays, you take the final random sample of households.

\section{Data Collection}

Data collection would involve how you would gather the data, given your hypothesis and your study design. If it is quantitative data you could use structured interviews, so as to get information as to the age of the respondents, the number of pregnancies, the use of contracetives and so on. Another approach is to use service statistics from the statistics you prepare for the 
local governments, provincial and then national. For example, the FHSIS and the CDLMIS that you prepared yourselves. But there are some limitations of this if not everybody submits this form to the province or to the central office in Manila, then they are not very accurate because they are not comprehensive enough. But I believe in the province level if you exert some efforts through the mayors or through the governors and then through the municipal health officer, perhaps this problem could be overcome. That would be a useful indicator of your program. But for as long as many are not submitting the forms then that is a useless source for the national government.

The other one is the self-administered questionnaire. This is used primarily if the respondents are well-educated because they understand the questions. The questionnaire should be well-constructed.

We also have the secondary sources such as surveys. One of these would be the National Census every ten years, the Population Census every five years or the National Demographic Survey and the like. For qualitative data you have structured interviews wherein instead of having a question with specified responses it could be an open ended question wherein you really probe to answer a particular question. Another one is a focus group discussion (FGD) which is a relatively new tool being used by sociologists. Usually an FGD has a facilitator and eight persons who are grouped together to discuss a particular topic to find out, for example, the reasons why clients drop-out of the FP program.

\section{Tabulation and Analysis of Data}

I am sure some of you have experienced using tick marks in trying to tabulate data. But there were times you experienced having errors. With the advent of computers, one can now carry out highly accurate tabulations for as long as you have organized codes for particular

questions and responses. With the use of program packages such as Microstat or SPSS, you can also do analysis of variance, regressions, correlations and the like. 
Let's say you plan to do a survey of potential users of NFP. You want to know the attributes of these respondents in terms of age, knowledge and so on. If you are getting an interval-type measure (that is to say, in continuous data) then you need to use the measures of central tendencies which are the mean, median, mode. Or it could be the measures of variation -- standard deviation, variance or range in order to get an inkling of the difference within the sample.

What kind of analytical procedures do we need to have in analyzing a data? You must be conscious of the types of measurement that you have. There are three kinds of measurements:

1. Nominal - you could classify things or persons according to certain categories like you could classify women according to religion or according to the color of their eyes or hair.

2. Ordinal - you could rank variables from 1, 2, 3, 4, or 5. For instance," What do Filipinos think about FVR's administration vis-a-vis the SPCPD?" Say 1 is strongly approve and 5 is strongly disapprove, that is an ordinal scale.

3. Interval - is a variable where the distance (or interval) between any two categories is known. For example, age: if you are 25 years old you are one year older than a 24 year old person. Likewise for 26 vs. 25 or 43 vs. 42 .

You also have to take into consideration the fact that, depending on the type of measurement that you have, you could apply certain types of statistical tests and establish certain specific relationships. An example is whether education has something to do with acceptance of NFP. If you measure "acceptance" by simply comparing acceptors to nonacceptors, you then have a nominal scale for your dependent variable. You will have to use chi-square or a test for difference of proportions. But if you measure acceptance in terms of the number of months that the couple has successfully used NFP you then have an interval scale, so other tools can be used, 
like ANOVA or multiple regression.

You can also use statistics to do some cost effectiveness analysis of a particular program. For instance: "What is the cost effectiveness of the natural family planning method?" In this example, you don't spend anything for contraceptives but you do spend a lot for the materials for the training program. So you want to know what would be the quantifiable benefits of all these? Benefits might be measured in terms of births averted or couple years of protection (CYP). So your question now becomes: "What does it cost to provide one couple year of protection through a training seminar for NFP? Or again, what is the comparative cost of the training seminar vs. some other approach.

A final thing to keep in mind is that sometimes you are working with two different data sets. For example, if you do a good job of keeping your service statistics, you should then be ready with accurate measures of your numerators for analysis. The problem here, though, is going to be your the denominator. I understand that there are some barangays or health clinics that maintain a record of MWRA or a record of children below four years old. If you have that, you can easily do certain measures about effects of programs or about fertility indicators. However, if you have no data on these, you need to have a survey because your FHSIS will only give you information on program inputs and outputs. You don't have the necessary data for your denominators to convert these service statistics to prevalence rates or other rates. 


\section{SUMMARY OF THE SESSION}

Michael A. Costello, Ph.D.

Let's go back to the by-now familiar OR cycle. We said that we should think of OR in terms of a process. One idea of process is historical, something evolving through time. We don't just do one step and stop there. No: we proceed as well to the next step so that it will be fully developed to get the most out of our OR study.

I am going to start with diagnosis and problem identification. That is what you are supposed to be doing tonight. I think it's alright that nobody automatically came up with an idea for their OR study because ideas that come very quickly usually are not very good. But please do talk with your batchmates from the LGU and try to come up with realistic problems that are confronting you on a day to day basis. Maybe I could give you some hint. Remember that Marilou said that the problems focused on topics that are under the control of the manager. What were they? Logistics, IEC, training, supervision, outreach, MIS, etc. So you might be thinking in terms of your problem identification as dealing with precisely any of those topics. If you want a good job on NFP, you better work on all those areas. But if you can't focus on

all, then maybe you can ask yourself, "Which of one of them is weakest?" That's one thing that might help you a little bit.

Testing an intervention is going to be another useful idea for you to think about. I understand what is going to go on here on the next few days. I heard that you have different NFP models that you are going to propose. Somebody should set up a study to see which model works best. Hopefully maybe they all would work. Or, then again, none of them might work and we have to go back to the drawing board. In any event, we see the need for data-based planning. You have to see if the model you are proposing will really work in the field. And that is what OR is all about. 
As Marilou reminded us, The OR cyle never stops. We can always go back and start another round. Just to give an example in workshop number 1, one of the buzzwords was counselling. Everybody thought we need quality of care, we need counselling and the midwives would give all the information and listen carefully to the women, etc. But let's say you have an intervention study and it turns out that, sure enough, the counselling is good, there are less dropouts, etc. Does that mean all our problems will be solved if we upscale this to put it in effect on an accross-the-board basis? Maybe not because the social system is interconnected. If we make a change over here in this little corner of a picture, that is going to affect everything else in the picture. Like the midwives might be spending so much time counselling that they are no longer giving polio shots or keeping up records in MIS. This means that there is still a need to see how the new program is going even after we proved that it worked in the pilot testing. We have to go back six months later and say: "Do you have any problems?" And they are going to answer: "Yes, why do you make us give counselling, it's taking so much of our time. Our midwives are rebelling, they are very unhappy about it." I am not saying that will happen, but the point is you go around the clock and it's possible and even necessary to go back and start a new cycle again because we've somehow changed the system. You always want to stay awake and know what's going on in the field. And that means OR, because OR gives us a systematic method that is a little bit better than just "seat of the pants type of management." Now we are collecting data which is hopefully scientific and objective and which will tell us the best strategies for coming up with a good program. 


\title{
DISSEMINATION OF RESEARCH FINDINGS
}

\author{
Edwin Reuel Ylagan, M.D. \\ The Population Council, Manila
}

\section{Introduction}

I will brief you on how dissemination is done. Again, for review, the major steps in the OR cycle are diagnosis, strategy selection, strategy testing, intervention and dissemination. In your OR Handbook one of the last chapters is about dissemination. As you can see, utilization and dissemination are crucial in the OR cycle.

An OR study does not end when an investigator writes and submits the final report. It has to be communicated, understood and acted upon. You can't just assume that this process will automatically take place. Why? Because

1. Final reports are often too long -- the program manager doesn't have time to read them.

2. Final reports are often too technical and may not be understood.

3. Even if you condense and simplify the final report, how do you know it will ever cross the desk of the real decision-maker? Or what if there are many program managers, like in a devolved set-up? You can't just leave these things to chance.

4. Even more follow-up will still be needed to go beyond dissemination to reach the goal of utilization.

\section{Dissemination of the Research Findings}

One of the implications of the above is that the researcher and the program manager must 
work together to plan a dissemination strategy.

This strategy must be built around three major decisions. The first of these is to identify the potential users of your study findings. Note that it might be possible at this point to identify two or more types of users. If so, separate strategies will be needed for each. For example, a one-page summary ("Executive Summary") of findings and implications will be needed for toplevel decision-makers, whereas a Research Dissemination Seminar might be more appropriately aimed at middle-level management. It can also be fruitful to develop news stories/ press releases for informing members of the general public.

A second decision will be to select those findings that will be of most interest and utility to each subgroup.

Your final decision has to do with the dissemination process. What type of communications strategy (seminar, research abstract, journal article, press release, etc.) will you use? As the handbook notes, "a good strategy will typically involve multiple media channels used repeatedly over a period of time to reach the largest audience possible."

The above comments should not be taken as downgrading the importance of the final research report. This, of course, is a very important document since it contains the evidence to back up all the claims being made in the seminars, press releases, and executive summaries.

So let's spend just a few minutes on the question, "How can I write an effective final report?" The next overhead suggests several answers to this question. To begin with, a very first consideration is, again, to identify your target audience. Reports written for program managers should not be the same as those written for scientists and academics. This latter group will want to scrutinize your study design, data collection procedures, statistical techniques, etc. But the program managers couldn't care less. They want practical advice about upgrading their program. 
Okay, let's assume for now that the main target audience consists of program managers. If so, several implications follow:

First, don't overload the report with technical considerations (e.g., sampling design). Such materials should be hidden away in a series of technical appendices.

Second, be sure to include a section on implications for programs and policies. Do a good job on this, too. (This may mean that the researcher will have to spend some time finding out just how the program is operating at present.)

Third, don't delay. Don't send over decision-relevant findings after the decision has already been made. One way of ensuring this is to submit brief interim reports on study findings as they come out. Releasing interim reports would also sustain the interest of your end-users or audience.

Fourth, prepare an Executive Summary.

Finally, "keep it simple." This means avoiding technical jargon and complicated statistical tables. Use clear words and relatively simple presentations of data -- e.g., bar charts, graphs, etc. 


\title{
UTILIZATION OF STUDY FINDINGS
}

\author{
Jocelyn Ilagan, M.D. \\ Department of Health, Family Planning Service
}

Though utilization maybe the last topic under operations research, I feel that it is the most important because if you don't utilize the final output of the study then it is not an OR. So let's always have that in our minds. We don't just stop at the written results but we have to make something out of the result and that is utilization.

There are several possible uses of OR findings:

1. To formulate or redirect national health and family planning policies.

2. Service delivery agencies can use them for strategic planning.

3. To identify key problem areas and focus attention on resources which can aid in solving these problems.

4. To evaluate performance and improve quality of service delivery

From these possible uses we could already identify the major users of our OR findings. As discussed earlier, these are the policy makers, district and state health authorities, local government units (LGUs), NGOs, media and international organizations/donors.

\section{Types of Utilization:}

1. individual changes and awareness

2. replication of research

3. focus improvement in size

4. larger changes in the system

5. national policy development 


\section{Factors Affecting Utilization:}

A. Positive factors (facilitators) -importance for key decision makers; policy relevance, coherence of results; and follow-up.

B. Negative factors(obstacles) - lack of shared vision; lack of span of control; timing and turn over; financing/logistics.

Lastly, I would like to present to you some suggestions for improving the utilization of our OR results:

1. Identify the decision-makers most likely to be interested in the study. Keep them informed about the study from its very beginning.

2. Continue involving these key decision-makers in every stage of the study. ("Ownership is a prerequisite for utilization.)

3. Do a good job on the section of your study report(s) entitled "Implications for Programs and Policy."

4. Make your dissemination seminar a vehicle for achieving greater utilization.

a. Allow plenty of time for reactions/suggestions/comments from the program managers in attendance.

b. Use discussion groups. The goal will be to develop an intra-agency action plan. 


\section{IDENTIFIED OR ISSUES}

[Listed below are some issues which are relevant for the NFP mainstreaming effort and which can be investigated with OR. Suggestions came from the participants during the brainstorming session held after Dr. Ilagan's talk on OR Utilization.]

\section{On Partnership}

1. Can a non-autonomous user (but NFP trained) nurse and midwife validate competency of the autonomous user (AU) of AU volunteer workers?

2. Can a non-autonomous NFP trained nurse or midwife supervise the autonomous user volunteer?

3. What are the factors that can facilitate competency in validation and supervision?

4. Can this mix of personnel (Non AU service provider + AU volunteer) deliver quality NFP service? (cf. the six elements of quality of care).

\section{On Training}

1. What training approaches and interventions are needed to bridge the "professional" and "non-professional" backgrounds of the partners (midwife/nurse and volunteer) in order to build/enhance teamwork?

2. What particular team building training course is best suited for service providers as specified by Model 4? 
3. What training designs are appropriate to volunteers and service providers for effective partnership and service provision?

\section{On IEC}

1. What is the most effective IEC strategy to use in order to attract new NFP clients in the public health sector? 


\section{LIST OF PARTICIPANTS}

OR-NFP Workshop

August 15-18, 1996

Boracay, Malay, Aklan

LGUs:

1. Lutgarda B. Ramirez

Nurse II

Provincial Health Office

Palawan

2. Dr. Magdalena I. Gonzales

PHO II

Provincial Health Office

Malolos, Bulacan

3. Divina B. Lumbo

Nurse IV

Provincial Health Office

Malolos, Bulacan

4. Luzviminda N. Muego

Provincial Population Officer

Provincial Population Office

Lingayen, Pangasinan

5. Betty Garrido

Provincial Population Officer

Provincial Population Office, Leyte

6. Dr. Lourdes F. Viterbo

Municipal Health Officer

Hilongos, Leyte

7. Dr. Rogelio Silapan

City Health Officer

City Health Office

Zamboanga City 
8. Mr. Generoso Celerio

Program Officer IV

Provincial Population Office

Zamboanga City

9. Dr. Sarah Vasquez

City Health Office

Legaspi City

10. Sarah Evasco

Nurse

City Health Office

Legaspi City

Resource Persons/Facilitators/Coordinators

11. Mr. Virgilio Aganon

The Population Council, Manila

12. Dr. Adelamar Alcantara

University of New Mexico, US

13. Dr. Florencia Apale DOH-FPS

14. Dr. Joseph Aricheta DOH-OPHS

15. Dr. Teresita Castillo

DOH-UNFPA PMT

16. Dr. Marilou P. Costello

The Population Council, Manila

17. Dr. Michael A. Costello

RIMCU, Xavier University

18. Ms. Letty Daga

DOH-FPS

19. Dr. Fely David

SSRI, Central Philippine University 
20. Ms. Esperanza Dowling PFNFP

21. Ephraim Despabiladeras OPHN-USAID

22. Ms. Feliciana Eraldo DOH-UNFPA PMT

23. Ms. Beth Ferraris INA I

24. Ms. Shirley Hampac INA I

25. Dr. Jocelyn Ilagan FPS, Department of Health

26. Ms. Trinidad Madrigal PFNFP

27. Ms. Araceli Maglaya PFNFP

28. Dr. Jonnalynn Mandelbaum DOH-IFPMHP, DA

29. Mr. Dominador Mondragon PFNFP

30. Mr. Joe Obordo PFNFP

31. Dr. Saumya RamaRao The Population Council, New Delhi

32. Ms. Mitos Rivera PFNFP

33. Ms. Myrna Seidman Institute of Reproductive Health, US Georgetown University, US 
34. Ms. Ann Wells

TWT Responsible Parenthood Association

35. Dr. Edwin Reuel Ylagan

The Population Council, Manila

36. Dr. Zelda Zablan

Population Institute, University of the Philippines 